\title{
EDITORIAL
}

\section{On Pushto, principles and passion: just what is an advance in psychiatric treatment?}

\author{
Mike Shooter
}

At the end of February, the College's Chief Examiner, Femi Oyebode, my wife and I went to Pakistan - to a conference in Peshawar at the foot of the Khyber Pass, just 100 miles from Kabul.

We went because I wanted to say thank you for the hospitality we received from the inaugural meeting of the British Pakistani Association last year. We went because it seemed particularly important for psychiatrists from East and West to be gathered together to talk about healing distress, just at the point when our politicians seemed hell-bent on creating more. And we went because it promised to be a good conference. It was, but not perhaps in the way I had expected.

Scattered through the programme were some remarkable examples of teams working with bravery and dedication in areas still shattered by war in Afghanistan, in refugee camps along the borders and with no resources among the poor of Pakistan itself. There were sessions on spirituality that seemed to echo our own growing disillusionment with an arid science. And all of it was conducted with the utmost respect for differences of opinion. But I also listened to lectures on risk assessment, on the management of patients, on their compliance with medication or resistance to its effects and to talk of cost-price units. It could have been anywhere in the NHS!

Then, right at the end of our stay, we were taken by Khalid Mufti, retiring President of the Pakistan Psychiatric Society, to see his unit in one of the most deprived areas of the city. There, with a small team of psychologists, nurses and trainees, he showed us what could be done with traumatised tribal soldiers who had seen their families blown apart in front of them, with women with psychoses and with boys whose short lives had been spent in heroin abuse - all mixed together, with little medication but bags of community support and good, oldfashioned, face-to-face, hands-on psychotherapy. It made me wonder just what is an 'advance' in psychiatric treatment, and what we might have lost in Western psychiatry in the name of progress.

That loss, I would suggest, is of the intimacy of the doctor-patient relationship and the joint 'ownership' of what, together, they might achieve. The results are similar on both sides - a learned helplessness in the face of forces that seem beyond their control or a retreat into mutual antagonism. Patients who have achieved power on a corporate level in the NHS feel little sense of participation in their own, individual treatment. Doctors feel blamed for clinical governance issues that are not their responsibility. It is the stuff that complaint and counter-complaint are made of.

The forces I speak of are both external and internal to the profession. Of the external ones, the most obvious are the political imperatives that undermine any sense of stability. It is difficult enough to have continuity of caring relationships within services whose configurations are changed from one year to the next, if commissioning processes for mental health services are threatened by lack of experience, motivation or scale within primary care trusts or their like, if the value of care is reduced to homogeneous cost-price units, and if the fear of waiting lists looms so large in the minds of chief executives that doctors reject the idea of giving them any more power over their employment contract, even to their own financial disadvantage. When the money for promised new community services fails to materialise, or the workforce on the acute ward is so stretched that the only contact with patients is over the drug-trolley, it is difficult to talk about therapeutic relationships at all.

Just as insidious is the drive to eliminate risk. Risk assessment is the order of the day and outcome measures are predicated on patient compliance with what is laid down. We have proposals for a new Mental Health Act that are built on the risk that patients might pose to themselves or others, rather than their need for treatment or their right to be given

Mike Shooter is the President of the Royal College of Psychiatrists (17 Belgrave Square, London SW1X 8PG, UK). 
it. In a post-Bristolian world, doctors must practice evidence-based medicine even if they do so within political constructs that have no evidence base whatsoever. Woe betide the clinician who strays outside the golden guidelines drawn up by one agency or another, for that way leads to the steps of the courthouse or the General Medical Council.

But relationships are a messy business, full of risk. The creativity of the therapeutic process lies in its ability to take those risks, on the basis of shared values, towards an outcome that might not be immediately obvious. To impose outcomes upon that process is to stifle it from the start. At the very best, we sacrifice patient autonomy and choice to the fear of uncertainty. At worst, we so alienate patients from our services that we increase the very risks we set out to reduce. By directing doctors' training towards the acquisition of technical knowledge, rather than the ability to understand distress and work with it in the rawness of relationships with our patients, we may induce a sense of safety - but destroy the self-fulfilment on which recruitment to psychiatry depends.

All of which takes us, of course, to the internal forces that are just as powerful as those imposed from outside. If time and workforce are a barrier to patient contact, so too are attitudes. 'Skills mix' is a glib phrase. It glosses over the fact that the skills may no longer be there to mix in professions that have learnt to 'manage', but have forgotten how to 'diagnose' and 'treat'. But it also depends on the willingness of doctors to share responsibilities. Sometimes, remarkably, the ones who bleat loudest about having too much work to spend quality time with their patients are the very ones who are loath to give up any bits of their job to others.

That sense of omnipotence can lead us into even bigger trouble. Just as the Government would like psychiatrists to become the guardians of public order, so the pharmaceutical companies would seek to tempt us into the medicalisation of human unhappiness. What's more, under the weight of patient expectations, doctors step all too often across the boundary between illness and non-illness, 'diagnosing' social deprivation and the behaviour that arises naturally from it. The result, rather than any dynamic relationship, is a passive fit between the patient's sickness role and the doctor's benevolent paternalism, or outright rejection (on both sides) if the patient's expectations outstrip the doctor's ability to satisfy them.
And thus, finally, to the thorny issue of stigma. We campaign quite rightly against the public prejudice on which our press and politicians seem to thrive. But can we be confident that it does not lurk inside us too? Ironically, many teams are redefining themselves around severe and enduring mental illness because the neuroses for which we abandoned it proved so hazy in their remit, so complex to treat, and their sufferers so difficult to engage. Yet our attitudes to such illness may not have changed all that much. Of course there are shortages of staff on most acute hospital wards, but the more staff are appointed, the more time they seem to spend in talking to each other - uncertain, perhaps, of their role but uncertain too of the 'unpleasantness' that might lie outside the canteen door.

So what am I asking for as I reach the end of my first year as President?

Not for a return to a mythical golden age of doctorpatient relationships. Certainly, when I first came into psychiatry, there was an intrinsic value to bringing patients into hospital, to spending the bulk of each day sharing their problems with other patients and staff, in a true 'asylum', away from the pressures of the world. But we often mistook laissez-faire for patient autonomy, while simultaneously opening the doors to difficulties that families might have been encouraged to find solutions for themselves.

Not for a Luddite-like resistance to all scientific progress. I do believe that psychiatry, of all medical specialities, should be more than technology. But good patient care depends on painstaking research into the causation of mental illness, its epidemiology and the medications that might relieve suffering sufficiently for therapeutic relationships to flourish.

And not for some Pushto fairytale in which resources don't matter as long as we have each other. That would be demeaning to the work of Khalid Mufti and his team, who would be the first to say that they could do even better work with more money, more staff and better facilities. But there was an 'innocence' about what they were doing that seemed to me to represent a humanity unsullied by politics, by fear of risk, by territorial battles, grandiose designs or doctor-patient mistrust. It roused in me the passion that brought me into psychiatry in the first place - the passion for helping human beings in distress, with little more than wisdom to draw upon.

That, surely, should be the aim that we are striving for. But where has it gone in all our progress? Who took the psychiatry out of psychiatry along the way? 